\title{
Historical notes on early neutron crystallography at the Oak Ridge Research Reactor \\ Bryan Chakoumakos ${ }^{1}$ \\ ${ }^{1}$ Oak Ridge National Lab \\ chakoumakobc@ornl.gov
}

The history of neutron sources for neutron scattering at Oak Ridge spans 78 yrs and was born from the Manhattan Project with the construction of the Graphite Reactor (aka X-10 Pile, 4 MW), which was built in 9 months and went critical on Nov 4, 1943. Neutron scattering research began with the Graphite Reactor, progressed to the Oak Ridge Research Reactor (ORR) (began operation May 29, 1958, 20 MW), then to the High Flux Isotope Reactor (HFIR) (began operating in 1966, $100 \mathrm{MW}$ ), where a cold source and guide hall were later added, and then finally the Spallation Neutron Source (SNS) was built. SNS and HFIR continue to operate, and development of a Second Target Station (STS) for SNS is underway. Anyone that works at ORNL becomes interested in the history, particularly of neutron science, since Oak Ridge is the birthplace of the field. The historical notes presented here are only a few examples of the crystallography contributions from the ORR, which was an important transition between the Graphite Reactor and the HFIR. In many ways, the ORR was a prototype for the HFIR and a springboard for the use of neutrons for chemical crystallography.

Bill Busing (ACA President, 1971) and his team including Henri Levy (ACA President, 1965) built the first automated 3-circle neutron diffractometer at the ORR in June 1961. The diffractometer had chi, phi and 2-theta motions and maintained a theta-2theta relationship by a lever system. Data collection was controlled by a computer program which prepared a paper control tape and a printed listing of the angles to be set. The diffractometer was mounted on the front face of the ORR and received a neutron beam via a monochromator directing the neutrons vertical from a horizontal beam tube. Seminal studies determining the structures of a variety of materials were undertaken with this instrument including the structure of sucrose and xenon fluorides. During this period, the Crystallography Group headed by Henri Levy in the ORNL Chemistry Division produced much of mathematical recipes and programs that would become the basis for modern-day, computer-based crystallography. The historical context of the ORR enabling chemical crystallography using neutrons is spotlighted in this presentation. 